Paidéia, 2005, 15(30), 93-104

\title{
ANÁLISE DE VARIÁVEIS BIOPSICOSSOCIAIS RELACIONADAS AO DESMAME PRECOCE ${ }^{1}$
}

\author{
Karina Camillo Carrascoza ${ }^{2}$ \\ Universidade Estadual de Campinas \\ Áderson Luiz Costa Júnior \\ Universidade de Brasília \\ Gláucia Maria Bovi Ambrozano \\ Antônio Bento Alves de Moraes \\ Universidade Estadual de Campinas
}

\begin{abstract}
Resumo: O objetivo deste estudo foi identificar alguns fatores que influenciam a ocorrência do desmame precoce, incluindo uma avaliação da influência do estresse vivenciado pela mãe na interrupção da amamentação natural. O estudo envolveu 40 mães cujos filhos eram atendidos pelo Centro de Pesquisa e Atendimento Odontológico para Pacientes Especiais - Cepae - FOP/UNICAMP. Como critério de inclusão no estudo, a mãe deveria ter realizado o desmame antes do sexto mês de vida da criança. A inclusão da mãe e coleta de dados ocorreu, no máximo, um mês após a interrupção da amamentação natural. As participantes foram entrevistadas individualmente, utilizando-se roteiro específico, e em seguida, foi aplicado o Inventário de Sintomas de Estresse (ISS). Os resultados mostraram uma relação positiva entre o retorno da mãe à sua rotina de trabalho, a manifestação de sintomas de estresse e a redução da produção de leite com o desmame precoce.
\end{abstract}

Palavras-chave: amamentação natural; desmame precoce; estresse.

\section{BIOPSYCHOSOCIAL VARIABLES ANALYSIS RELATED TO EARLY WEANING}

Abstract: The objective of this study was to identify factors that influence early weaning occurrence, including an assessment of the stress experimented by mother's influence on breastfeeding interruption. The study comprised 40 mothers whose children were treated by Research and Dental Treatment Center for Special Patients - FOP - UNICAMP. As an inclusion criterion in the study, weaning should have taken place before the child was six months old. Mother inclusion and data collection occurred, at most, one month after breastfeeding interruption. The participants were interviewed individually, using a particular script, and then, the Inventory of Stress Symptom (ISS) was applied. Results showed a positive relation among mother's coming back to work, demonstration of stress symptoms and decreased milk production with the early weaning.

Key-words: breastfeeding; early weaning; stress.

\section{Introdução}

Apesar de todo o conhecimento acumulado e das campanhas de divulgação sobre os efeitos positivos do aleitamento materno para o crescimento

\footnotetext{
${ }^{1}$ Artigo recebido para publicação em 10/12/2004; aceito em 07/03/ 2005

2 Endereço para correspondência: Karina Camillo Carrascoza, Rua: Goiânia, $n^{\circ}$ 63, apto. 401 - Bairro Nossa Senhora de Fátima CEP:13478-660, Americana/SP, E-mail: karinacarras@ig.com.br
}

físico e para o desenvolvimento da criança, alguns estudos brasileiros (Caldeira \& Goulart, 2000; Costa, Figueiredo \& Silva, 1993; Vieira, Glisser, Araújo \& Sales, 1998) apontam altos índices de desmame precoce, anteriores ao sexto mês de vida do bebê, tanto em amostras brasileiras quanto em populações pesquisadas de outros países.

Com objetivo de esclarecer este fenômeno, a investigação das variáveis que levam à maior pro- 


\section{Karina Camillo Carrascoza}

babilidade de ocorrência de desmame precoce constitui um dos temas que tem despertado grande interesse de pesquisadores em ciências da saúde. Costa, Figueiredo e Silva, (1993), por exemplo, avaliaram a prática do aleitamento materno entrevistando 100 mães de lactentes até três anos de idade, em consultórios particulares e ambulatórios de pediatria na cidade de Belém (Pará). Os principais motivos referidos para o desmame parcial foram a diminuição do volume de leite $(40,0 \%)$ e a necessidade de retorno às atividades profissionais (21,2\%), enquanto que os motivos do desmame completo referiram-se à recusa do lactente em mamar (36,7\%) e à diminuição do volume de leite (28,2\%).

Moura (1997) investigou a época do desmame parcial e total, bem como as causas alegadas para o desmame precoce, entrevistando 259 mães de crianças de 12 a 24 meses de idade, em um serviço público de pediatria também na cidade de Belém (Pará). Embora apenas 3,9\% das crianças tenham recebido leite de vaca (fórmula láctea) no período neonatal, mais de $62 \%$ das mães ofereceram chá e/ou água a seus bebês ainda no primeiro mês de vida. As justificativas mais freqüentes para tal administração incluíram a ocorrência de episódios de cólicas, gases e suspeitas de sede da criança. Somente $18,5 \%$ dos lactentes foram completamente desmamados antes dos seis primeiros meses de vida, sendo que $62,6 \%$ mantiveram a amamentação, concomitante a outros alimentos, por 12 ou mais meses. As mães explicaram o desmame total, ainda no primeiro semestre de vida de seus filhos, referindo-se, com maior freqüência, à recusa da criança em mamar no peito $(62,5 \%)$ e à falta de leite (peito seco), com $12,5 \%$.

McLeod, Pullon e Cookson (2002) investigaram a prática do aleitamento materno em 490 mulheres norte-americanas que, durante o período de gestação, manifestavam o desejo de amamentar seus filhos. As 192 mulheres (pouco mais de 39\%) que interromperam a amamentação natural antes de seis meses de vida do bebê, apresentaram os seguintes argumentos: "bebê faminto" (25\%), "bebê agitado" (18\%), "pouco leite" (18\%), e "necessidade de retorno ao trabalho" (5\%). Mais de $77 \%$ das mães gostariam de ter amamentado seus filhos por mais tempo. Por outro lado, 21\% consideram adequada a duração do aleitamento materno e apenas $2 \%$ preferiam ter amamentado seus filhos por um período de tempo menor ao efetivamente utilizado.

Além da identificação de argumentos maternos para o desmame precoce, alguns estudos têm investigado o enfrentamento de situações estressantes e seus efeitos sobre a amamentação. Variáveis biológicas e psicossociais da gestante/mãe e algumas variáveis ambientais têm sido apontadas como intervenientes sobre esta relação. Os estudos se referem, principalmente, a três situações potencialmente estressantes:

1. Quando a mãe enfrenta dificuldades para iniciar a amamentação ainda na maternidade (Taddei, Westphal, Venâncio, Bogus \& Souza, 2000), destacando-se a ausência de alojamento conjunto mãe-bebê. Quando esta situação está associada à falta de preparo dos profissionais de saúde para orientar as mães sobre os procedimentos a serem adotados, especificamente relacionados à estimulação da produção de leite, a probabilidade de ocorrência de desmame precoce aumenta significativamente (Oliveira \& Leal, 1997).

2. Quando há confrontação entre a tarefa de amamentar e a execução de outras atividades domésticas (Ichisato \& Shimo, 2002), podendo ocorrer distúrbios imunológicos e psicofisiológicos, que reduzem a produção de leite e a autoconfiança materna, interferindo sobre o estabelecimento e manutenção das relações de vínculo com o bebê (Martins Filho, 1987).

Para Carrascoza (2004), o receio de não estar atendendo às necessidades nutricionais do bebê, por exemplo, aumenta quando aparecem os chamados "Inimigos do Aleitamento Materno", tais como as sugestões de complementação alimentar com mamadeira de água, chás e sucos de fruta. A introdução precoce de outros alimentos, além de desnecessária, pode interromper a sucção do bebê ao seio (o bico de borracha altera o reflexo da sucção). No entanto, a autora ressalta que muitas mães aderem à facilidade da mamadeira, rejeitando o uso de copo ou xícaras, cujo manuseio é mais trabalhoso, exige maior dedicação e cuidado para ser administrado à criança.

3. No momento de retorno ao trabalho (enquanto atividade ocupacional), geralmente entre o segundo e o quarto mês de vida do bebê (Oliveira \& Leal, 1997; Rea, Venâncio, Batista, Santos \& Greiner, 1997), a mãe é obrigada a alterar a rotina de cuidados com o bebê e 
disponibilizar agentes, individuais ou institucionais, para cuidar da criança durante sua ausência.

Alguns estudos, no entanto, apontam que o trabalho não é, necessariamente, incompatível com o aleitamento materno. Para Dowling, Meier, Difiori, Blatz e Martin (2002), exigências de treino, dedicação e o manejo de algumas variáveis contextuais, tais como coletar o leite materno e deixá-lo à disposição de um agente cuidador da criança para administração em copinhos, podem garantir condições mais saudáveis de desenvolvimento à criança, mesmo que a mãe tenha que se ausentar durante várias horas do dia.

Outros estudos apontam que as condições de trabalho da mãe são determinantes para a percepção de maior ou menor estresse desta atividade em relação à amamentação. Issler, Enk, Azeredo e Moraes (1994), entrevistaram 137 mães de crianças até 36 meses de idade, que estavam em creches na cidade de Porto Alegre (Rio Grande do Sul), analisando o tempo de amamentação e sua relação com creches junto ao local de trabalho (creches internas) e creches distantes do local de trabalho (creches externas). A prevalência de amamentação aos 3, 6 e 12 meses foi de $60 \%$, $26 \%$ e $7 \%$, respectivamente, sendo identificada uma correlação estatística e significativa entre presença das crianças em creches internas e duração da amamentação superior a 3 meses. Os autores sugerem que a proximidade das creches internas com o local de trabalho proporcionava maior tranqüilidade e segurança às mães. Observou-se que a pouca quantidade de leite materno $(41,7 \%)$ e a rejeição ao peito $(25,0 \%)$ foram as principais razões alegadas para o desmame completo das crianças. Pouco mais de $10 \%$ das mães pararam de amamentar devido à necessidade de retorno ao trabalho.

Para Osis, Duarte, Pádua, Hardy, Sandoval e Bento (2004), a existência da creche no local de trabalho constitui um elemento relevante para a manutenção do aleitamento após a licença de maternidade, especialmente o materno exclusivo. A decisão sobre quanto tempo amamentar de forma exclusiva esteve relacionada às informações recebidas acerca do assunto antes e durante a gestação, e no pós-parto.

Segundo Dewey (2001), um certo nível de estresse é perfeitamente aceitável quando se consideram os eventos que envolvem o nascimento de uma criança e seus cuidados, embora, na maioria dos ca- sos, o início da lactação não seja significativamente afetado. Entretanto, Dewey destaca que mães e bebês que vivenciam altos níveis de estresse, como modificações freqüentes na rotina de cuidados, têm grandes chances de sofrer alguns efeitos adversos, orgânicos e psicossociais.

Considerando que o estresse constitui um estado fisiológico (dor, cansaço, exaustão) ou emocional (ansiedade, frustração, ambivalência) que interfere sobre a capacidade de adaptação a situações do dia-a-dia (Dewey, 2001), dois mecanismos, descritos por Lana (2001), podem explicar a relação entre estresse e lactação:

1. Em condições de estresse, o organismo da mãe aumenta a liberação de adrenalina, que provoca vasoconstrição generalizada. Quando a vasoconstrição é muito intensa, a prolactina e ocitocina (hormômios envolvidos na produção do leite) não chegam às células lactóforas e mioepiteliais da mama, respectivamente, comprometendo a produção de leite. Assim, o desmame precoce pode ser um efeito adverso do enfrentamento de situações estressantes.

2.Bebês que vivenciaram situações de estresse durante o trabalho de parto podem apresentar-se fracos ou muito sonolentos, dificultando a evocação dos reflexos de preensão e sucção eficiente da mama. A falta de sucção não gera estímulos neuroendócrinos responsáveis pela liberação dos hormônios envolvidos na produção do leite e comprometem a lactação.

Pode-se afirmar que o estudo do aleitamento materno envolve aspectos relacionados a diversas especialidades da saúde, tais como questões nutricionais do bebê, condições psicossociais da relação mãe-criança, indicadores de desenvolvimento infantil, saúde geral e saúde bucal da criança, assim como um amplo espectro de fatores culturais e familiares predisponentes do aleitamento prolongado e do desmame precoce. Os estudos que buscam identificar as variáveis que influenciam a duração do aleitamento materno, determinando as causas do desmame precoce, contribuem para o aprimoramento de profissionais de saúde treinados na identificação de fatores de risco do desmame precoce e incentivadores da adesão da mãe a programas de aleitamento prolongado.

A partir da consideração destas variáveis, o objetivo deste trabalho foi identificar alguns fatores que determinam a ocorrência do desmame precoce, 


\section{Karina Camillo Carrascoza}

avaliando a influência do estresse percebido pela mãe para a interrupção da amamentação natural.

\section{Metodologia}

Participaram deste estudo 40 mães que acompanham seus filhos ao Centro de Pesquisa e Atendimento Odontológico para Pacientes Especiais (Cepae) da Faculdade de Odontologia de Piracicaba (FOP) da Universidade Estadual de Campinas (UNICAMP).

Apesar de o Cepae realizar, também, o atendimento de pacientes portadores de deficiências físicas e/ou mentais, a amostra deste Estudo foi constituída apenas por pacientes sadios, considerados especiais pelo fato de se encontrarem em uma fase do desenvolvimento que requer um ambiente de cuidados e um sistema diferenciado de atendimento à saúde.

À medida que o aleitamento materno era interrompido, a qualquer momento de vida da criança, do primeiro ao sexto mês, as mães eram incluídas na pesquisa. Assim, para que a mãe fosse incluída neste Estudo, ela deveria ter realizado o desmame antes do sexto mês de vida da criança e, o intervalo entre o desmame, a realização da entrevista e aplicação do Inventário de Sintomas de Stress (Lipp \& Guevara, 1994) foi inferior a 30 dias, tempo máximo previsto para que a aplicação deste instrumento seja sensível ao resgate dos sintomas de estresse percebidos em eventos passados.

A amostra foi selecionada a partir de 158 mães atendidas pelo Cepae no período de março de 2002 a outubro de 2003. Das 158 mães, 51 atendiam a estas condições e 40 (78\% da amostra elegível para o estudo) foram selecionadas aleatoriamente. A Tabela 1 apresenta dados sócio-demográficos e principais características das Participantes deste Estudo, incluindo, entre outros, idade, escolaridade, renda, estado civil e experiência prévia em amamentação.

As mães foram entrevistadas e avaliadas individualmente, em sessão única. As entrevistas foram gravadas em fitas de áudio (K-7), para registro de maior número de dados e posterior transcrição "ipsis literis". Utilizou-se um roteiro específico, elaborado com objetivo de permitir a obtenção de dados referentes à idade e motivo do desmame precoce, período de retorno ao trabalho e enfrentamento de dificuldades durante a amamentação, referidas como variáveis relevantes pela literatura. As entrevistas tiveram duração média de 30 minutos cada.

Em seguida, foi aplicado o Inventário de Sintomas de Estresse (ISS), desenvolvido por Lipp e Guevara (1994), e respondido por escrito e individualmente, de modo a garantir privacidade e evitar constrangimentos durante a escolha das respostas pelos participantes. A aplicação tinha o objetivo de investigar se as mães lembravam dos sintomas que apresentaram quando da interrupção da amamentação e se estes sintomas incluíam sinais clínicos e/ou comportamentais de estresse, bem como o tipo de sintoma existente (somático ou psicológico) e a fase do estresse em que se encontrava, conforme critérios descritos pelos autores. O tempo de aplicação do ISS variou de 25 a 30 minutos para cada participante.

O ISS baseia-se na hipótese de que os efeitos do estresse podem se manifestar tanto na área somática quanto cognitiva e que aparecem em seqüência e hierarquia de gravidade na medida em que o processo do estresse se desenvolve. O instrumento é composto por três partes. Na primeira parte, a respondente assinala, de um total de 15 itens, os sintomas físicos ou psicológicos que tenha experimentado nas últimas 24 horas. Na parte 2, ela assinala, de um total de 15 itens, os sintomas experimentados na última semana. Finalmente, na parte 3, ela assinala, de um total de 23 itens, os sintomas experimentados no último mês. Cada parte corresponde a uma fase específica de estresse (alerta, resistência e exaustão). $\mathrm{Na}$ análise das respostas, soma-se um ponto para cada sintoma assinalado em cada uma das três partes. Para cada fase, está definido um limite mínimo de pontos para o diagnóstico da presença de estresse: seis pontos (alerta), três pontos (resistência) e oito pontos (exaustão). Se a respondente obtiver valores superiores aos limites, é possível especificar a fase de estresse na qual se encontra, bem como se a manifestação de estresse é mais acentuada na área cognitiva ou somática.

As respostas das mães às entrevistas foram categorizadas e os dados inseridos em planilhas do Software Microsoft Excel (versão 7.0), sendo submetidos à estatística descritiva em termos de freqüência e porcentagem. Posteriormente, os Testes Quiquadrado e Exato, de Fisher, foram utilizados para avaliar se havia relação estatística entre as seguintes 
Tabela 1: Características das mães.

\begin{tabular}{|c|c|c|}
\hline & $\mathbf{N}$ & $\%$ \\
\hline TOTAL & 40 & 100,0 \\
\hline \multicolumn{3}{|l|}{ Idade da mãe } \\
\hline$<20$ anos & 14 & 35,0 \\
\hline$\geq 20$ anos & 26 & 65,0 \\
\hline \multicolumn{3}{|l|}{ Escolaridade da mãe } \\
\hline$\leq 5$ anos & 7 & 17,5 \\
\hline$>5$ anos & 33 & 82,5 \\
\hline \multicolumn{3}{|l|}{ Renda familiar } \\
\hline$<2$ salários mínimos & 11 & 27,5 \\
\hline$\geq 2$ salários mínimos & 29 & 72,5 \\
\hline \multicolumn{3}{|l|}{ Estado civil } \\
\hline Vive com o pai da criança & 35 & 87,5 \\
\hline Não vive com o pai da criança & 5 & 12,5 \\
\hline \multicolumn{3}{|l|}{ Mãe trabalha fora } \\
\hline Sim & 15 & 37,5 \\
\hline Não & 25 & 62,5 \\
\hline \multicolumn{3}{|l|}{ Número de filhos } \\
\hline 1 & 22 & 55,0 \\
\hline 2 ou mais & 18 & 45,0 \\
\hline \multicolumn{3}{|c|}{ Experiência prévia em amamentação* } \\
\hline Sim & 7 & 17,5 \\
\hline Não & 33 & 82,5 \\
\hline \multicolumn{3}{|c|}{ Orientação sobre amamentação nesta gestação } \\
\hline Sim & 27 & 67,5 \\
\hline Não & 13 & 32,5 \\
\hline \multicolumn{3}{|l|}{ Tipo de parto } \\
\hline Cesárea & 22 & 55,0 \\
\hline Normal & 18 & 45,0 \\
\hline \multicolumn{3}{|c|}{ Permanência em alojamento conjunto } \\
\hline Sim & 36 & 90,0 \\
\hline Não & 4 & 10,0 \\
\hline \multicolumn{3}{|c|}{ Tempo de início da amamentação após o parto } \\
\hline$<8$ horas & 26 & 65,0 \\
\hline$\geq 8$ horas & 14 & 35,0 \\
\hline
\end{tabular}

* Foi considerado que a mãe tinha experiência em amamentação se ela amamentou pelo menos um filho até o sexto mês de vida.

variáveis: (a) idade de desmame da criança $\mathrm{X}$ motivo referido para o desmame; (b) idade de desmame da criança X apresentação de sintomas de estresse pela mãe; e (c) motivo referido para o desmame X apresentação de sintomas de estresse pela mãe. Estes três cruzamentos mostraram relação estatística com p<0,05.
O projeto de pesquisa foi submetido à apreciação do Comitê de Ética em Pesquisa da FOP/ UNICAMP, tendo sido aprovado pelo protocolo $\mathrm{n}^{\circ}$ 014/2002. Todas as participantes assinaram o Termo de Consentimento Livre e Esclarecido, conforme especifica a Resolução No. 196/96 do Conselho Nacional de Saúde (CNS). 


\section{Karina Camillo Carrascoza}

\section{Resultados}

Considerando o período do desmame precoce, observou-se que $42,5 \%$ dos casos ocorreram entre o segundo e o terceiro mês após o parto e
22,5\% entre o terceiro e quarto mês, conforme demonstrado na Figura 1. Ainda é possível destacar que $17,5 \%$ das crianças não completaram o segundo mês de vida em aleitamento, sendo expostas a um desmame extremamente precoce.

Figura 1: Distribuição de freqüência de desmame anterior ao sexto mês de vida da criança (desmame precoce).

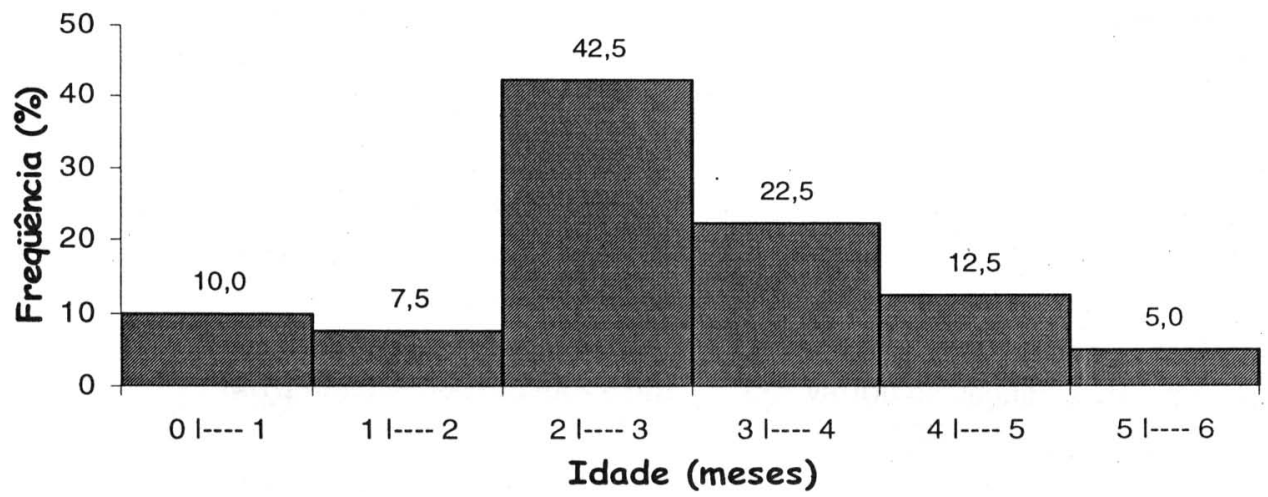

Segundo a Figura2, o principal motivo referido pelas mães para a ocorrência do desmame precoce foi a "falta natural” foi alegada por 30\% das mães como causa do desmame, destacando-se o ingurgitamento mamário e as de leite” (45\%). A “dificuldade durante a amamentação fissuras mamilares como os problemas mais comuns.

Figura 2: Distribuição de freqüência do motivo alegado pela mãe para a ocorrência do desmame precoce.

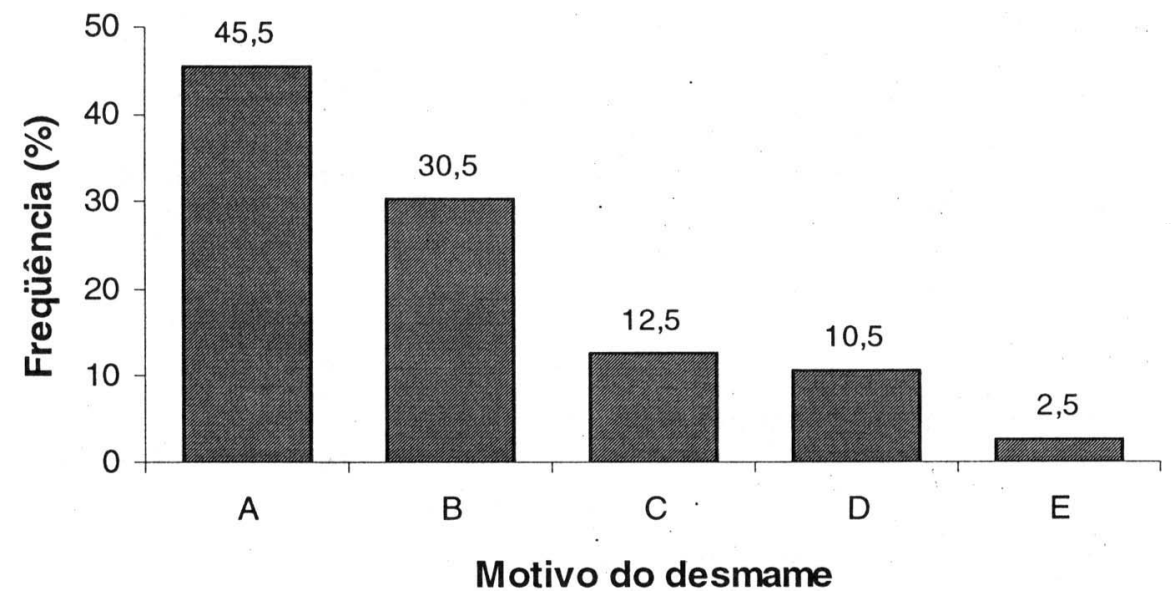
Legenda: A) Falta de leite B) Dificuldade durante a amamentação C) Trabalho materno D) Doença da mãe ou criança E) Conselho médico.

Pode-se observar, na Figura 3, que durante os primeiros seis meses de vida da criança, a "falta de leite”, principal motivo para a interrupção da amamentação natural não se limitou a uma determinada idade da criança, embora não tenha sido referido como motivo para o desmame entre o primeiro e segundo mês de vida da criança. As mães que desmamaram seus filhos no primeiro mês de vida utiliza- ram como motivos a "falta de leite" e a "dificuldade durante a amamentação". O argumento de "trabalho materno" como motivo para o desmame apareceu, pela primeira vez, a partir do segundo mês de vida do bebê e teve percentual crescente até o sexto mês. Os principais motivos alegados para a realização do desmame, entre o quarto e o sexto mês de vida da criança, foram o "trabalho materno" e a "falta de lei- 
te”. O argumento de "doença da mãe ou da criança” como motivo de desmame apareceu apenas durante o segundo e terceiro mês de vida da criança. A rela- ção entre a idade de desmame da criança e o motivo referido para o desmame foi estatisticamente significativa com $\mathrm{p}<0,05$.

Figura 3: Distribuição de freqüência do motivo referido pela mãe para a ocorrência do desmame precoce em função da idade da criança (Teste Qui-Quadrado $\mathrm{p}<0,05$ ).

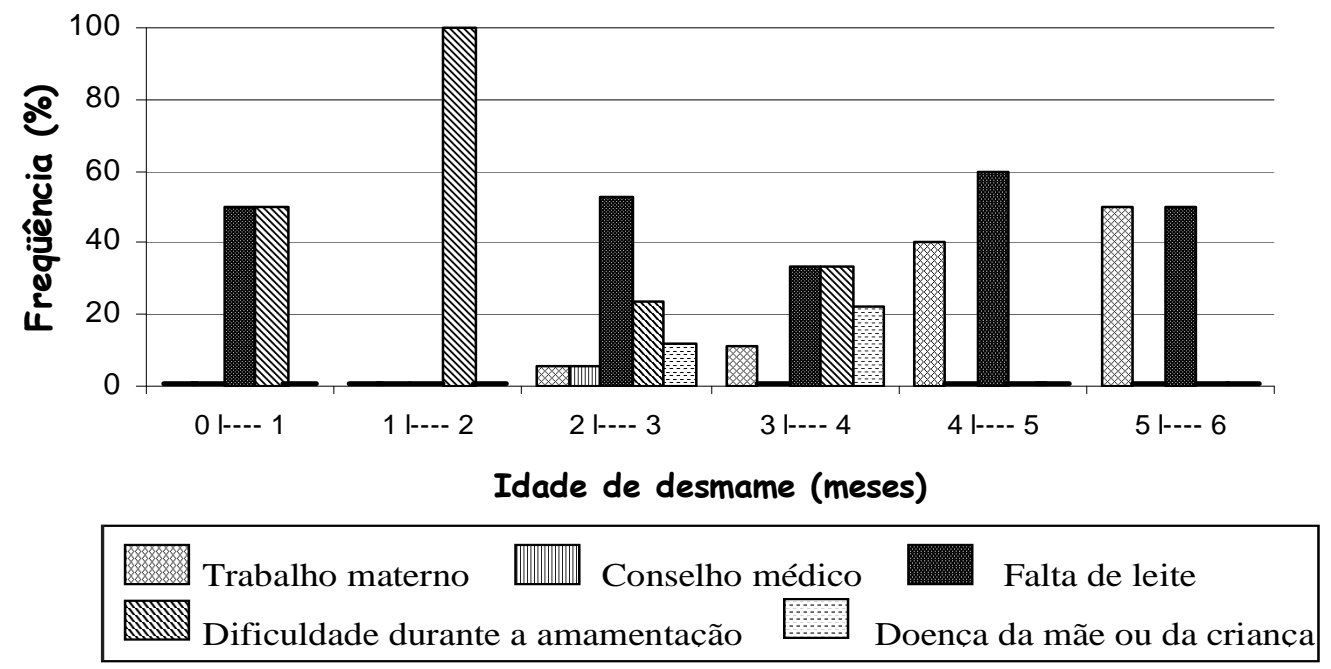

Entre as 40 participantes do Estudo, 25 (62,5\%) referiram sintomas de estresse quando efetuaram 0 desmame, indicado pelo ISS. Todas as 25 mães que apresentaram estresse estavam na fase de resistência, sendo que cinco apresentavam sintomas predominantemente físicos e 20 predominantemente psicológicos. A relação entre a idade de desmame da criança e a lembrança de sintomas de estresse pelas mães foi estatisticamente significativa $\operatorname{com} \mathrm{p}<0,05$. A Figura 4 mostra o percentual de sintomas de estresse em função da idade de desmame da criança. Observou-se que $75 \%$ das mães ( $\mathrm{N}=4$ mães) que desmamaram seus filhos durante o primeiro mês e $77 \%$ ( $N=17$ mães) que interromperam o aleitamento entre o terceiro e o quarto mês de vida da criança, apresentaram estresse. $O$ fato de que $100 \%$ das mães que desmamaram seus filhos entre o quinto e o sexto mês de vida da criança apresentarem estresse deve ser interpretado com cautela, pois apenas duas mães interromperam a amamentação neste período.

Figura 4: Percentual de sintomas de estresse da mãe em função da idade de desmame precoce da criança (Teste Exato de Fischer $\mathrm{p}<0,05$ ).

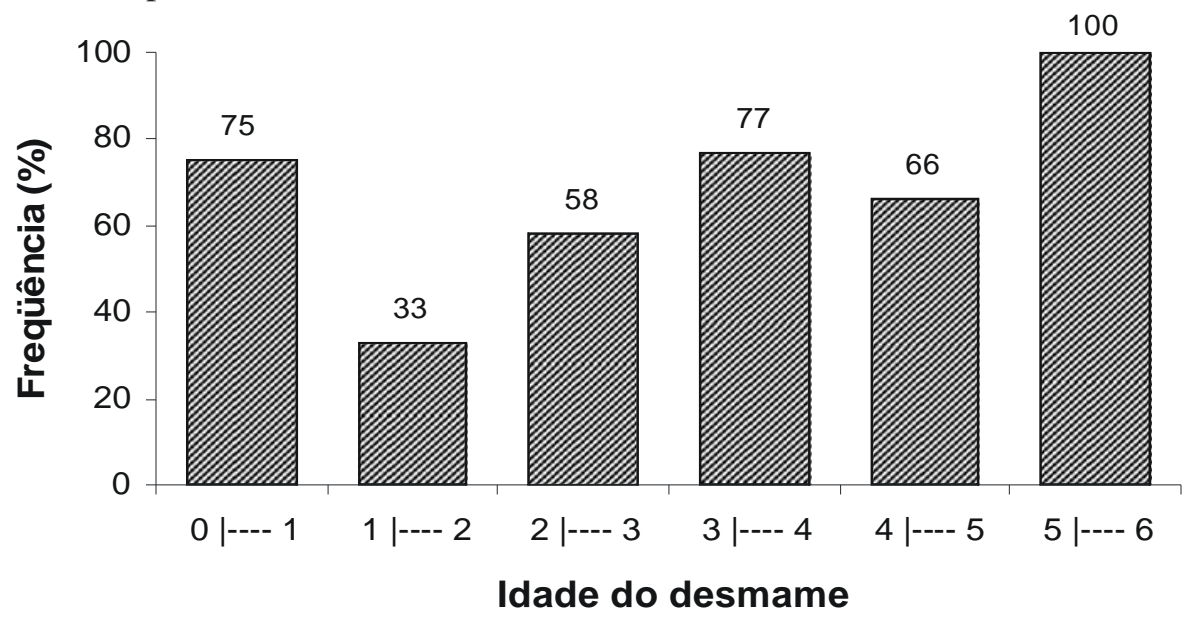




\section{Karina Camillo Carrascoza}

A Figura 5 mostra a distribuição das 25 mães que apresentaram estresse, em função dos motivos referidos para a ocorrência do desmame. O maior índice de estresse foi observado entre as mães que alegaram "conselho médico" (100\% / N=1). A freqüência de ocorrência de estresse entre as mães que referiram os outros motivos para a realização do des- mame foi muito semelhante: "falta de leite” (66\% / $\mathrm{N}=18)$, "trabalho materno" (60\% / N=5), "dificuldades durante a amamentação" e "doença da mãe ou da criança” (50\% / N=4). A relação entre o motivo referido para o desmame e a lembrança de sintomas de estresse pelas mães foi estatisticamente significativa com $\mathrm{p}<0,05$.

Figura 5: Apresentação de sintomas de estresse da mãe em função do motivo referido para a ocorrência do desmame precoce (Teste Exato de Fischer $\mathrm{p}<0,05$ ).

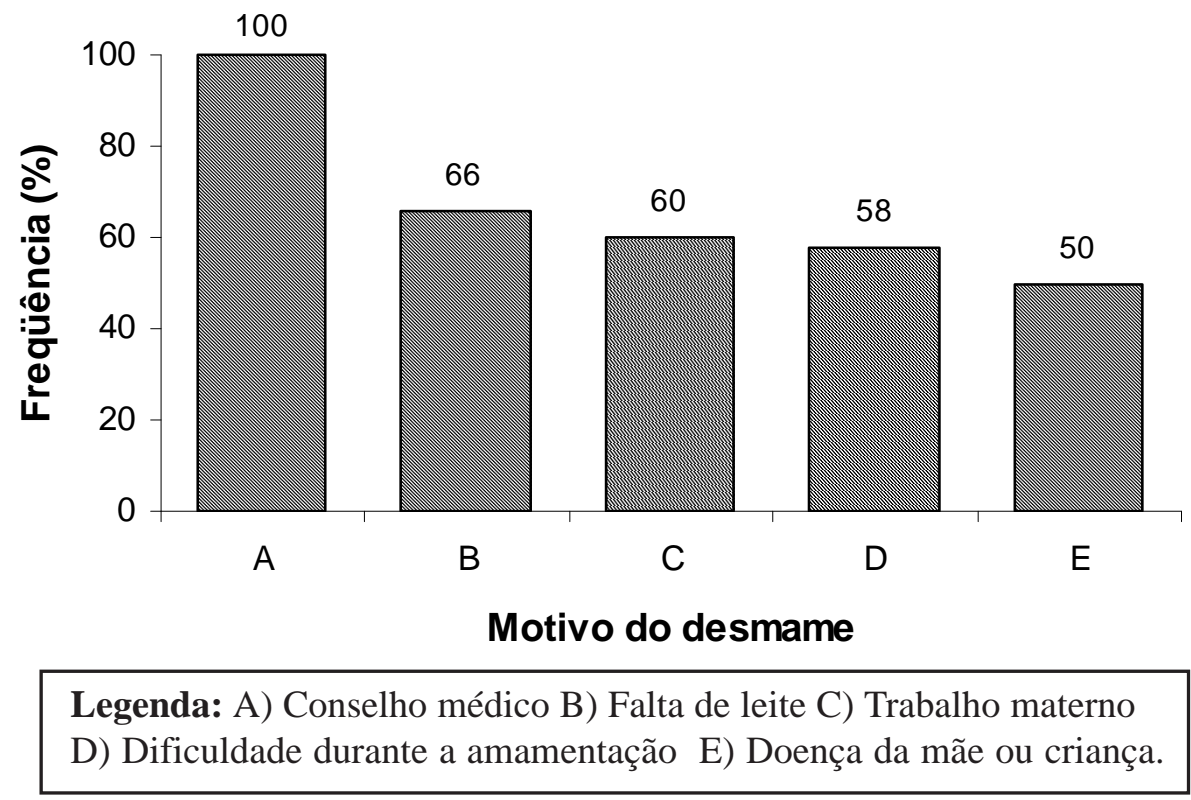

\section{Discussão}

A grande incidência de desmame ao longo do terceiro mês de vida da criança, observada neste Estudo, é semelhante aos resultados obtidos por Souza e cols. (1991), Carvalhaes, Parada, Manoel e Venâncio (1998) e Gigante, Victora e Barros (2000), que relacionam esta ocorrência ao estresse do término da licença-maternidade e o retorno da mãe ao trabalho.

Rea e cols. (1997) destacam que o período de licença-maternidade tem sido utilizado pela maioria das mães como uma garantia para a amamentação, embora outros fatores sejam fundamentais para a manutenção da lactação, tais como a proximidade mãe-criança e/ou a retirada periódica de leite materno, durante o reinício da jornada de trabalho. Segundo Fein e Roe (1998), o trabalho em tempo integral, após um período de licença-maternidade, diminui a duração da amamentação de forma significativa, enquanto que o trabalho em tempo parcial (seis, quatro ou menos horas por dia) não afeta, significativamente, a duração da amamentação.

A interrupção extremamente precoce da amamentação natural (antes do segundo mês de vida) se deve, conforme relato das mães deste estudo, às dificuldades encontradas durante a prática do aleitamento, o que é compatível com a observação de Nakano (2003), segundo o qual a crença de que a amamentação é um processo natural, e que qualquer mulher é capaz de vivenciá-lo sem problemas ou dificuldades, não se observa na experiência clínica. Para Ramos e Almeida (2003), é essencial que nas primeiras semanas de vida da criança, a mãe receba apoio e orientação, a fim de amenizar a insegurança e a ansiedade comumente vivenciadas, favorecendo a manutenção do aleitamento materno por maior período de tempo (Ramos \& Almeida, 2003).

Nesta fase, o organismo da mãe passa por uma série de alterações, adaptando-se às necessidades do 


\section{Análise de variáveis biopsicossociais 101}

bebê. Segundo Lana (2001), uma das dificuldades freqüentemente observadas é a produção excessiva de leite durante as primeiras semanas após o parto. Esta síntese de leite em abundância ocorre para garantir leite suficiente para amamentar, em certas ocasiões, mais de um filho. Com o passar dos dias, a quantidade de leite produzida vai se ajustando ao volume de leite ingerido pela criança, culminando na redução da produção de leite e no tamanho das mamas. Mas, enquanto esta adaptação não ocorre, pode haver um acúmulo de leite nas mamas, especificamente nas ampolas lactóforas (local onde o leite é armazenado), levando a um processo de ingurgitamento. O relato mais freqüente das mães, observado ao longo da experiência clínica obtida junto ao Cepae, é que as mamas estão “empedradas” ou “com caroços”. Nestes casos, o leite não escoa, há sensação de dor intensa e o mamilo torna-se plano, dificultando, ou mesmo impossibilitando, a amamentação natural. Quando o processo de ingurgitamento não é tratado, pode evoluir para quadros de mastite (acúmulo de leite associado a processo inflamatório) e abscessos (Wamback, 2003).

Uma das dificuldades para amamentar, referidas com freqüência pelas mães do presente estudo foi o aparecimento de fissura nos mamilos, cuja ocorrência está associada, na maioria dos casos, a técnicas incorretas de pega do mamilo durante a sucção (a criança exerce preensão apenas sobre o mamilo, ao invés do mamilo e aréola), à forma inadequada de retirada da criança do peito e à falta de exposição das mamas ao sol (Carrascoza, 2004). A fissura é a principal causa da sensação dolorosa durante o ato da amamentação natural, levando à maior probabilidade da introdução de outras formas de alimentação.

A alta freqüência do relato de falta de leite pelas mães deste Estudo confirma os trabalhos de Park e Berlin (1981), Costa e cols. (1993), Del Ciampo, Ricco, Muchillo, Betiol e Daneluzzi. (1994), assim como Caldeira e Goulart (2000), que apontaram a hipogalactia como o principal motivo, alegado pelas mães, para a ocorrência de desmame precoce. Nestes estudos, observou-se que as mulheres que acreditavam produzir uma quantidade insuficiente de leite materno apresentavam como justificativas o volume diminuído das mamas, a pouca drenagem espontânea de leite e o choro da criança após a mamada.
Segundo Arantes (1995), as hipogalactias primárias são raras, sendo difícil obter das mães respostas confiáveis, especialmente por meio de entrevista e em estudos transversais, pois as participantes tendem a dar respostas socialmente mais convenientes e que não agridam sua auto-estima. A autora conclui que o fato de o bebê não querer mais mamar e o leite se tornar insuficiente são razões finais do processo. Observa-se que no momento de desmame completo, a mãe passa a mencionar que desmamou porque ela própria não queria amamentar e, também, porque o leite secou. Arantes relaciona a hipogalactia ao fim da licença-maternidade, pois quando a mãe retorna ao trabalho inicia-se um processo de diminuição da freqüência de mamadas e do período de sucção, além da introdução de outros alimentos. Estes eventos diminuem a estimulação da glândula mamária, levando à diminuição do volume de produção láctea.

Scott, Diet, Landers, Hughes e Binns (2001) apontam que as dificuldades encontradas pela mãe, no início da amamentação, constituem a principal causa para a ocorrência do desmame antes do sexto mês de vida da criança. Observa-se, no entanto, que os casos de fissuras, ingurgitamento mamário, mastite e mamilo plano ou invertido podem ser facilmente resolvidos se diagnosticados e tratados logo após seu surgimento. Na maioria dos casos, a mãe não sabe a quem recorrer logo após a alta hospitalar (período no qual tais problemas são mais freqüentes), já que o retorno ao pediatra é marcado, geralmente, quando a criança completa o primeiro mês de vida.

A distribuição homogênea da argumentação de "falta de leite" dentre os casos de interrupção do aleitamento materno durante os primeiros seis meses de vida da criança, pode ser explicada pelo fato da hipogalactia constituir o resultado final do processo de desmame e não a causa deste, como sugere o trabalho de Arantes (1995). Considerando que a "falta de leite" consiste na razão final do processo de desmame, os dados obtidos neste estudo sugerem que o principal motivo para o desmame, nos primeiros dois meses de vida, estava relacionado à dificuldade(s) enfrentada(s) durante a amamentação natural, reforçando os dados discutidos anteriormente. De forma semelhante à análise realizada para os motivos de desmame nos dois primeiros meses de vida da criança, pode-se sugerir que o principal motivo para o desma- 


\section{Karina Camillo Carrascoza}

me entre o quarto e o sexto mês de vida da criança foi o "retorno ao trabalho", já que a "falta de leite” referida pelas mães não pode ser considerada uma causa.

A baixa referência ao "trabalho materno" como causa para a ocorrência do desmame precoce sugere duas hipóteses: (a) outros fatores estão relacionados à alta incidência de desmame precoce por volta do terceiro mês de vida da criança; e (b) o retorno ao trabalho leva a uma redução da produção de leite e à introdução de outros tipos de alimentos na dieta da criança, refletindo, portanto, na alta freqüência de referência à "falta de leite".

O estudo de Mahgoub, Bandeke e Nnyepi (2002), aponta o trabalho da mãe fora do lar como uma causa importante para ocorrência do desmame precoce. Já para Silva, Almeida, Novak, Carvalho, e Silva, (1997), a diminuição da amamentação não é determinada diretamente pelo trabalho da mulher, mas pelas condições sociais concretas em que se realiza, por exemplo, as grandes distâncias entre casa e trabalho e a ausência de creches e de intervalos para amamentação.

A crescente presença da mulher no mercado de trabalho, associada a mudanças estruturais na sociedade e na família, forçou o surgimento de dispositivos legais de proteção à amamentação da mulher que trabalha. A Constituição Federal de 1988, em seu artigo $7^{\circ}$, parágrafo XVIII, garante "licença maternidade, sem prejuízo do emprego e do salário, com duração de 120 dias”. A Consolidação das Leis Trabalhistas (CLT) também protege a mulher trabalhadora e nutriz, prevendo: descansos especiais durante a jornada de trabalho, creches ou convênios com creches para empresas com mais de 30 funcionárias em período fértil e locais adequados para os cuidados com os lactentes. Apesar de leis que garantem a manutenção da amamentação, grande parte das mulheres desconhece seu conteúdo ou não usufrue dos benefícios disponíveis.

Segundo Brown, Poag e Kasprzycki (2001), a presença de posto de coleta ou extração de leite constitui uma iniciativa favorável à amamentação em locais de trabalho sem creche. Por ser uma iniciativa relativamente nova, deve ser acompanhada de intensa divulgação. Se as mães não souberem extrair ou ordenhar seu leite, por exemplo, ou não forem orientadas para tal (fato que raramente ocor- re nas maternidades), a criação deste espaço pode ser inútil.

Quanto às creches fora do local de trabalho, embora populares, trazem a dificuldade da distância para a manutenção da amamentação nos pequenos períodos de pausas e almoço, mesmo quando a empresa cumpre a lei. Segundo Rea e cols. (1997), este benefício não interfere no tempo de duração da amamentação, se comparado com o encontrado em trabalhadoras que não dispõem de creche no local de trabalho. Aponta-se como de extrema importância, a criação de uma estrutura de apoio à nutriz trabalhadora, para que o retorno ao trabalho, após a licença maternidade, não signifique a interrupção precoce da amamentação com conseqüências deletérias à saúde infantil.

Apesar do "conselho médico" como causa de desmame precoce não ter sido representativo, tornase uma questão preocupante, já que, segundo uma das mães deste estudo, o pediatra orientou a interrupção da amamentação, uma vez que esta não possuía leite suficiente para alimentar seu filho. A mãe foi orientada a introduzir fórmula láctea na mamadeira, ao invés de ser incentivada a restabelecer a amamentação por meio de técnicas de realeitamento e estímulo à sucção.

Segundo Carrascoza (2004), apesar dos estudos que investigam as variáveis relacionadas à amamentação apontarem para fatores relativamente comuns, observa-se uma certa resistência (ou mesmo falta de conhecimento) de alguns profissionais de saúde, representados na sua maioria por pediatras e obstetras. Por um lado, nutricionistas, enfermeiros, psicólogos, fonoaudiólogos e odontólogos têm incentivado a amamentação natural exclusiva até o sexto mês de vida da criança, ensinando condutas clínicas para a solução de eventuais problemas de mama (mamilo plano, fissuras, ingurgitamento, mastite). Por outro lado, alguns pediatras têm orientado a substituição ou complemento das mamadas por mamadeira com fórmula infantil, ou ainda pior, com leite de vaca, além da introdução extremamente precoce de outros tipos de alimentos. Frente a problemas de mama, alguns pediatras e obstetras preferem interromper a lactação e introduzir outra forma de alimentação, ao invés de adotar condutas compatíveis com a amamentação natural. A situação torna-se mais 
preocupante ao considerar-se que os médicos ainda detêm o maior poder potencial de influência sobre o repertório de crenças e comportamentos das mães.

Os dados obtidos por este Estudo apontam algumas variáveis que poderiam ser abordadas por profissionais de saúde que atuam junto a gestantes, de modo a estimular o aumento dos índices de aleitamento materno prolongado. Estudos multicêntricos e com amostras ampliadas devem constituir um dos objetivos das pesquisas que avaliam os efeitos de variáveis psicossociais sobre o desmame precoce.

\section{Referências Bibliográficas}

Arantes, C. I. S. (1995). Amamentação - visão das mulheres que amamentam. Journal of Pediatrics, 71, 195-202.

Brown, C. A., Poag, S. \& Kasprzycki, C. (2001). Exploring large employers' and small employers' knowledge, attitudes, and practices on breastfeeding support in the workplace. Journal of Human Lactation, 17, 39-46.

Caldeira, A. P. \& Goulart, E. M. A. (2000). A situação do aleitamento materno em Montes Claros, Minas Gerais: estudo de uma amostra representativa. Journal of Pediatrics, 76, 65-72.

Carrascoza, K. C. (2004). Fatores determinan-tes do desmame precoce e do aleitamento materno prolongado. Dissertação de mestrado, Faculdade de Odontologia, UNICAMP, Piracicaba.

Carvalhaes, M. A. B. L., Parada, C. M. G. L., Manoel, C. M. \& Venâncio, S. Y. (1998). Diagnóstico da situação do aleitamento materno em área urbana do sudeste do Brasil: utilização de metodologia simplificada. Revista de Saúde Pública, 32, 430436.

Costa, C. O. M., Figueiredo, E. M. \& Silva, S. B. (1993). Aleitamento materno: causas de desmame e justificativa para amamentar. Journal of Pediatrics, 69, 176-178.

Del Ciampo, L. A., Ricco, R. G., Muchillo, G., Betiol, H. \& Daneluzzi, J. C. (1994). Influências dos tipos de alojamento conjunto sobre recém-nascidos na prática do aleitamento materno. Journal of Pediatrics, 70, 10-15.
Dewey, K.G. (2001). Maternal and fetal stress are associated with impaired lactogenesis in humans. Journal of Nutrition, 131, 3012-3015.

Dowling, D. A., Meier, P. P., Difiori, J. M., Blatz, M. A. \& Martin, R. J. (2002). Cup-feeding for preterm infants: Mechanics and safety. Journal of Human Lactation, 18, 13-18.

Fein, S. B. \& Roe, B. (1998). The effect of work status on initiation and duration of breast-feeding. American Journal of Public Health, 88, 10421046.

Gigante, D. P., Victora, C. G. \& Barros, F. C. (2000). Nutrição materna e duração da amamentação em uma coorte de nascimentos de Pelotas-RS. Revista de Saúde Pública, 34, 259-265.

Ichisato, S. M. T. \& Shimo, A. K. K. (2002). Revisitando o desmame precoce através de recortes da história. Revista Latino-Americana de Enfermagem, 10, 578-585.

Issler, R. M. S., Enk, I., Azeredo, P. R. \& Moraes, J.A. (1994). Estudo comparativo do período de aleitamento materno de crianças em creches internas e externas. Journal of Pediatrics, 70, 287-290.

Lana, A. P. B. (2001). O Livro de estímulo à amamentação: uma visão biológica, fisiológica e psicológica comportamental da amamentação. São Paulo: Atheneu.

Lipp, M. N. \& Guevara, A. H. (1994). Validação empírica do Inventário de Sintomas de Estresse. Estudos de Psicologia, 11(3), 43-9.

Mahgoub, S. E. O., Bandeke, T. \& Nnyepi, M. (2002). Breastfeeding in Botswana: practices, attitudes, patterns, and the socio-cultural factors affecting them. Journal of Tropical Pediatrics, 48, 195-199.

Martins Filho, J. (1987). Como e porque amamentar. São Paulo: Sarvier.

Mcleod, D., Pullon, S. \& Cookson, T. (2002). Factors influencing continuation of breastfeeding in a cohort of women. Journal of Human Lactation, 18, 335-343. 


\section{Karina Camillo Carrascoza}

Moura, E. F. A. (1997). Duração do período de aleitamento materno de crianças atendidas em ambulatório de pediatria. Journal of Pediatrics, 73, 106-110.

Nakano, A. M. S. (2003). As vivências da amamentação para um grupo de mulheres: nos limites de ser "o corpo para o filho" e de ser "o corpo para si”. Caderno de Saúde Pública, 19, 355-363.

Oliveira, M. I. C. \& Leal, M. C. (1997). Alojamento conjunto e parto cesáreo em maternidades do Estado do Rio de Janeiro, Brasil. Revista de Saúde Pública, 31, 575-580.

Osis, M. J. D., Duarte, G. A., Pádua, K. S., Hardy, E., Sandoval, L.M. \& Bento, S. F. (2004). Aleitamento materno exclusivo entre trabalhadoras com creche no local de trabalho. Revista de Saúde Pública, 38(2), 172-179.

Park, T. K. \& Berlin, P. (1981). Prevalence of exclusive and extended breastfeeding among rural korean women. Yonsei Medicine Journal, 22, 108-121.

Ramos, C. V. \& Almeida, J. A. G. (2003). Aleitamento materno: como é vivenciado por mulheres assistidas em uma unidade de saúde de referência na atenção materno-infantil em Teresina, Piauí. Revista Brasileira de Saúde Materno Infantil, 3, 315-321.

Rea, M. F., Venâncio, S. I., Batista, L. E., Santos, R. G. \& Greiner, T. (1997). Possibilidades e limitações da amamentação entre mulheres trabalhadoras formais. Revista de Saúde Pública, 31, 149-156.

Scott, J. A., Diet, G. D., Landers, M. C. G., Hughes, R. M. \& Binns, C. W. (2001). Psychosocial factors associated with the abandonment of breastfeeding prior to hospital discharge. Journal of Human Lactation, 17, 24-30.

Silva, V. G., Almeida, J. A. G., Novak, F. R., Carvalho, N. V. \& Silva, L. G. P. (1997). O uso de drogas e o aleitamento materno. Jornal Brasileiro de Ginecologia, 107, 171-188.
Souza, L. S. F., Souza, E. L. S., Barretto, M. R. R., Ramos, R. T. T., Macedo, J. J. B. \& Serra, C. R. (1991). Determinantes do êxito do aleitamento natural. Journal of Pediatrics, 6, 42-50.

Taddei, J. A. A. C., Westphal, M. F., Venâncio, S., Bogus, C. \& Souza, S. (2000). Breastfeeding training for health professionals and resultant changes in breastfeeding duration. São Paulo Medicine Journal, 118(6), 185-191.

Vieira, G. O., Glisser, M., Araújo, S. P. T \& Sales, A. N. (1998). Indicadores do aleitamento materno na cidade de Feira de Santana, Bahia. Journal of Pediatrics, 74, 11-16.

Wamback, K. A. (2003). Lactation mastitis: A descriptive study of the experience. Journal of Human Lactation, 19, 24-34. 